\title{
Atividade Lúdica na Fisioterapia em Pediatria: Revisão de Literatura ${ }^{\mathbf{1}}$ Playing in Pediatric Physical Therapy: Literature ReVieW
}

\author{
Allan dos Santos da SILVA ${ }^{2}$ \\ Paola Janeiro VALENCIANO ${ }^{3}$ \\ Dirce Shizuko FUJISAWA ${ }^{4}$
}

\begin{abstract}
RESUMO: a criança desenvolve as habilidades motoras, cognitivas, comportamento emocional e moral por meio da brincadeira e da interação social, que continuam no decorrer da vida. A variedade de jogos e/ou brincadeiras contextualiza e favorece o desenvolvimento motor adequado, sendo fundamental para aprendizagem motora. O presente estudo teve como objetivo investigar a utilizaçáo do lúdico como recurso terapêutico na prática da fisioterapia pediátrica, por meio da revisão bibliográfica nas bases de dados indexadas: PubMed, Cochrane, Medline e Lilacs, utilizando-se as palavras-chave "Child", "Play and Playthings", "Physical Therapy Modalities" com o operador booleano "and". Foram levantados 15 estudos, sendo cinco sobre a utilizaçáo da atividade lúdica por meio de jogos e brincadeiras, nove por meio de jogos eletrônicos e realidade virtual e um envolvendo ambas as modalidades. As categorias mostraram benefícios e boa aceitação pelas crianças envolvidas: melhora na postura e equilíbrio corporal, motivação, fortalecimento de vínculo, maior mobilidade, redução de sintomas de dor, fadiga, ansiedade e distúrbios de sono; a melhora da função de assoalho pélvico, melhora no desempenho físico, equilíbrio, destreza, força de preensão e movimentação dos membros superiores e maior satisfação com a terapia.
\end{abstract}

PALAVRAS-CHAVE: Desenvolvimento Infantil. Fisioterapia. Educação Especial.

\begin{abstract}
The child develops motor, cognitive, emotional and moral behavior through play and social interaction, which continue throughout life. The variety of games and/or games contextualizes and provides adequate motor development, and is fundamental for motor learning. The present study aimed to investigate the use of play as a therapeutic resource in the practice of pediatric physical therapy, through a bibliographic review in the indexed databases: PubMed, Cochrane, Medline and Lilacs, using the keywords "Child", "Play and Playthings", "Physical Therapy Modalities" with the Boolean operator "and". A total of 15 studies were collected including five on the use of play activity through games and play, and nine through electronic games and virtual reality, and one involving both modalities. The categories showed benefits and good acceptance by the involved children: improved posture and body balance, motivation, bond strength, greater mobility, reduction of pain symptoms, fatigue, anxiety and sleep disorders; improvement of pelvic floor function, improvement in physical performance, balance, dexterity, grip strength and upper limb movement, and greater satisfaction with therapy.
\end{abstract}

KEYWORDS: Special Education. Child Development. Physical Therapy.

\section{INTRODUÇÃo}

O desenvolvimento na infância é global e complexo, já que envolve tanto os aspectos como crescimento, maturação neuromotora e do sistema pulmonar, quanto à aprendizagem, aquisiçôes motoras, linguagem e variáveis psicossociais (MOURA-RIBEIRO; GONÇALVES, 2010; POUSTIAUX, 2004). Considera-se o período neonatal de zero a 28 dias de vida, primeira infância ou lactente de 29 dias a dois anos, pré-escolar de dois a seis anos, escolar de sete a nove anos e adolescência de 10 aos 19 anos (BRASIL, 2002; ABRANTES; LAMOUNIER; COLOSIMO, 2002). Devido às especificidades de cada faixa etária considerada na infância,

\footnotetext{
${ }^{1}$ http://dx.doi.org/10.1590/S1413-65382317000400011

2 Acadêmico do Curso de Graduação em Fisioterapia da Universidade Estadual de Londrina/UEL, Londrina, PR, Brasil. allans893@gmail.com

${ }^{3}$ Doutoranda do Programa Associado UEL/UNOPAR em Ciências da Reabilitação, Londrina, PR, Brasil: paola_jv3@hotmail.com

${ }^{4}$ Docente do Curso de Graduação em Fisioterapia da Universidade Estadual de Londrina e do Programa Associado UEL/UNOPAR em Ciências da Reabilitação. Londrina, PR, Brasil. dirce_fujisawa@uel.br
} 
os serviços pediátricos e os profissionais envolvidos devem considerar as particularidades anatômicas, fisiológicas e do desenvolvimento infantil, pois nessa fase os indivíduos apresentam condiçóes clínicas e necessidades diferenciadas quando comparados ao adulto (POUNTNEY, 2008; SCHENKEL et al., 2013).

A fisioterapia em pediatria consiste em avaliar, planejar e desenvolver um programa de intervenção individualizado. A avaliação envolve os seguintes aspectos: limitações ou alteraçóes, habilidades/ funcionalidade, motivação e queixas, o que permite a elaboração do programa de intervenção considerando as necessidades da criança e da família (FUJISAWA; MANZINI, 2006). Reavaliações, orientações e educação também são à base do programa terapêutico (CORDEIRO, 2007). Santos, Ramos e Sousa (2011) destacam a importância da abordagem pediátrica humanizada na fisioterapia, em que o profissional considere o paciente como ser distinto e pessoal; além de levar em consideração o aspecto lúdico, por exemplo, ao utilizar de ambientes alegres, recursos musicais e visuais atraentes, permitir a habituação ao local de terapia; e a afetividade ao ser carinhoso, pegar no colo, conversar, acalmar e sorrir.

Associar a brincadeira na fisioterapia torna os atendimentos mais toleráveis e prazerosos, facilitando a interação da criança com o terapeuta, uma vez que o brincar, faz parte da infância (BRUNELLO et al., 2006). Somado a isso, é por meio da brincadeira e interação social que a criança progressivamente irá desenvolver as habilidades motoras, cognitivas, comportamento emocional e moral, que continuarão no decorrer da vida (FEIGELMAN, 2009). Dentre os facilitadores e mediadores do tratamento, ao considerar a população pediátrica, sabe-se que "o brincar e o brinquedo" são os mais eficazes do ponto de vista motivacional, já que esses são reconhecidamente importantes e habituais na infância (BORGES; NASCIMENTO; SILVA, 2008).

O instrumento lúdico não deveria ser usado como forma de subordinação ou recompensa para criança na terapia (SANTOS; FERREIRA, 2013), pois os jogos e/ou brincadeiras, quando, apropriadamente, utilizados e guiados pelo fisioterapeuta, contextualizam e favorecem comportamentos motores desejados em terapia, sendo fundamentais para a aprendizagem motora (FUJISAWA; MANZINI, 2006). Estudos têm mostrado diversos recursos lúdicos utilizados como coadjuvantes terapêuticos, com potenciais benefícios à população pediátrica. Outra possibilidade também é o uso desses recursos como atividade recreativa (AZEVEDO, 2007). Com isso, dentre as diversas maneiras de usar atividade lúdica na fisioterapia em pediatria, pode-se diferenciar, ou até mesmo categorizar as modalidades conforme as particularidades e objetivos de cada paciente. Em relação aos recursos lúdicos criados para terapia em crianças com afecçóes respiratórias, Schenkel et al. (2013) destaca o soprar bola de sabão; apito; fazer bolhas com canudinho na água; soprar bolinhas de isopor, cata-vento, pena, folha de papel, língua de sogra; simular o soprar vela de bolo de aniversário; promovendo desobstrução pulmonar e higiene brônquica. Além disso, estabelecer o vínculo terapeuta-paciente, a integração da criança à terapia e tornar os exercícios mais toleráveis e atrativos, contribui para melhor aderência e potencializa o efeito terapêutico desejado.

Outras pesquisas que abordam o lúdico como coadjuvante, têm mostrado benefícios quanto à potencialização dos desfechos, como por exemplo, a imersão na realidade virtual (RV) em crianças com disfunçóes neurológicas e exercícios lúdicos criados para fins terapêuticos na 
fisioterapia respiratória (SCHENKEL et al., 2013; SILVA; IWABE-MARCHESE, 2015). Silva e Iwabe-Marchese (2015) utilizaram a RV na reabilitação motora de crianças com Paralisia Cerebral e obtiveram melhora do equilíbrio estático e dinâmico, motivação, diversão, melhora do desempenho físico e cognitivo.

Tendo em vista a importância da atividade lúdica no contexto da fisioterapia pediátrica, busca-se identificar os efeitos obtidos com o uso da atividade lúdica nos diferentes desfechos fisioterapêuticos para a população pediátrica, por meio de revisão de literatura. Além disso, pretende-se verificar as funçóes atribuídas e as diversas modalidades de atividades lúdicas utilizadas nos atendimentos fisioterapêuticos.

\section{Método}

Foi realizada revisão bibliográfica por meio de análise e integração da literatura a respeito da utilização da atividade lúdica na fisioterapia em pediatria. O levantamento bibliográfico foi realizado em Outubro/2015 a junho/2016, por meio das bases de dados indexadas: PubMed, The Cochrane Library, Medical Literature Analysis and Retrieval System Online (MEDLINE) e Lilacs, revisados por um juiz, sem restrição de ano de publicação e de idioma, utilizando os descritores "Child"," Play and Playthings", "Physical Therapy Modalities" intercaladas pelo operador booleano "and”. Foram incluídos artigos completos disponíveis eletronicamente; trabalhos cuja população alvo era pediátrica (zero a 19 anos); estudos experimentais ou quase-experimentais; estudos qualitativos e/ou quantitativos; e excluídos estudos de natureza observacional, estudos não disponíveis eletronicamente, artigos que não foram publicados em periódicos indexados, e revisóes de literatura.

Para análise dos dados, extraíram-se informaçóes que permitiram caracterizar os artigos em relação ao tipo de estudo, amostra, país e local em que foi desenvolvido, e os dados relativos à modalidade terapêutica empregada, medidas de desfecho e efeitos obtidos com o uso da atividade lúdica. Posteriormente, essas informaçóes foram analisadas e os conteúdos similares foram agrupados em categorias.

\section{Resultados E discussão}

Foram encontrados mediante a busca em base de dados 89 artigos, entretanto 74 foram excluídos, pois não atendiam aos critérios de inclusão, sendo que, 21 artigos não estavam disponíveis eletronicamente em sua versão completa; outros quatro artigos não utilizaram a população infantil; 44 artigos não utilizaram o lúdico como abordagem fisioterapêutica; por fim, foram excluídos mais quatro artigos de natureza de revisão e um por não se tratar de artigo publicado em periódico indexado. Os 15 artigos selecionados para o estudo foram analisados detalhadamente para melhor compreensão e organização, sendo possível categorizar o uso da atividade lúdica para os diferentes desfechos e populaçóes pediátricas.

Foram incluídos 15 estudos, realizados entre os anos 1999 e 2014 . Do total, cinco $(33,3 \%)$ estudos utilizaram a atividade lúdica sem o envolvimento de mídia tecnológica, caracterizados então na modalidade jogos e brincadeiras, enquanto, nove (60,0\%) utilizaram jogos eletrônicos e RV como recurso terapêutico na fisioterapia em pediatria (Quadros 1 e 2). 
Somente um (6,6\%) artigo envolvia ambas as modalidades terapêuticas de atividade lúdica e foi categorizado como modalidade mista.

\begin{tabular}{|c|c|c|c|c|c|}
\hline Autor/Ano & Método e Intervenção & Local & Amostra & Medidas & Resultados \\
\hline $\begin{array}{l}\text { Jill, Heathcock, } \\
\text { Galloway (2009) }\end{array}$ & $\begin{array}{l}\text { Tipo de estudo: Ensaio } \\
\text { clínico controlado rando- } \\
\text { mizado; } \\
\text { Material: Brinquedos para } \\
\text { bebês; } \\
\text { Método: } \\
\text { G1: Grupo de treinamento } \\
\text { de movimento com intera- } \\
\text { çâo física com brinquedos } \\
\text { (n=13); } \\
\text { G2: Grupo de treinamento } \\
\text { social com uso de CD com } \\
\text { música infantil por } 10 \\
\text { minutos e interação com a } \\
\text { família. } \\
\text { Duraçáo do treinamento: } \\
\text { oito semanas, cinco sessóes } \\
\text { *Ambos os grupos } \\
\text { realizaram } 10 \text { minutos de } \\
\text { treino em casa, } 5 \mathrm{x} / \text { semana } \\
\text { (realizado treinamento e } \\
\text { manual de instruçóes). }\end{array}$ & $\begin{array}{l}\text { País: Estados } \\
\text { Unidos. } \\
\text { Local: La- } \\
\text { boratório de } \\
\text { comporta- } \\
\text { mento motor } \\
\text { infantil e o } \\
\text { domicílio. }\end{array}$ & $\begin{array}{l}\text { Faixa etária: oito } \\
\text { semanas de idade } \\
\text { corrigida. } \\
\text { Crianças prematuras } \\
\text { (idade gestacional } \\
\text { menor que } 33 \text { se- } \\
\text { manas e peso menor } \\
\text { que } 2500 \mathrm{~g} \text { ). } \\
\mathrm{n}=27\end{array}$ & $\begin{array}{l}\text { Número de conta- } \\
\text { tos pé-brinquedo; } \\
\text { Duração (segun- } \\
\text { dos) do contato } \\
\text { pé-brinquedo; } \\
\text { Gravaçóes por } \\
\text { meio de câmera de } \\
\text { vídeo analisadas no } \\
\text { computador. }\end{array}$ & $\begin{array}{l}\text { Na sessão antes do } \\
\text { treinamento, o con- } \\
\text { tato pé-brinquedo } \\
\text { foi mais frequente } \\
\text { do que com as mâos; } \\
\text { Após a sessäo 1, } \\
\text { as crianças do G1 } \\
\text { tiveram contato } \\
\text { mais frequente e de } \\
\text { maior duraçấo com } \\
\text { o brinquedo do que } \\
\text { as do G2. }\end{array}$ \\
\hline $\begin{array}{l}\text { Thygeson et al. } \\
(2010)\end{array}$ & $\begin{array}{l}\text { Tipo de estudo: Ensaio } \\
\text { clínico. } \\
\text { Material: tapetes de Yoga } \\
\text { Método: meditaçấo no } \\
\text { início e final da sessão, exer- } \\
\text { cícios de manutençăo do } \\
\text { equilíbrio, postura, flexão e } \\
\text { extensão da coluna vertebral } \\
\text { e técnicas de relaxamento. } \\
\text { Duraçấo: uma única sessaáo } \\
\text { de } 45 \text { minutos }\end{array}$ & $\begin{array}{l}\text { País: Estados } \\
\text { Unidos } \\
\text { Local: } \\
\text { Unidade de } \\
\text { reumatologia } \\
\text { e oncologia }\end{array}$ & $\begin{array}{l}\text { Faixa etária: } 6 \text { a } 18 \\
\text { anos; } \\
\text { Câncer e doenças do } \\
\text { sangue } \\
\mathrm{n}=11 \text { crianças, } \\
\text { cinco adolescentes e } \\
33 \text { familiares. }\end{array}$ & $\begin{array}{l}\text { Sensação de bem- } \\
\text {-estar por meio da } \\
\text { escala: } \\
\text { Spielberger State } \\
\text { Anxiety; } \\
\text { IDATE- Inventá- } \\
\text { rio de ansiedade } \\
\text { Traço-Estado; } \\
\text { Questionário } \\
\text { STAIC. }\end{array}$ & $\begin{array}{l}\text { O Yoga diminuiu os } \\
\text { sintomas de descon- } \\
\text { forto, dores, fadiga, } \\
\text { ansiedade, falta de } \\
\text { equilíbrio e per- } \\
\text { turbaçóes do sono. } \\
\text { Além de melhorar a } \\
\text { manutençáo postural } \\
\text { e ser usado como } \\
\text { recurso lúdico. }\end{array}$ \\
\hline $\begin{array}{l}\text { Huang; Galooway } \\
\text { (2012) }\end{array}$ & $\begin{array}{l}\text { Tipo de estudo: Relato de } \\
\text { pesquisa. } \\
\text { Materiais: Carro Fisher Pri- } \\
\text { ce Lightening McQueen TM } \\
\text { e materiais para adaptaçăo } \\
\text { Materiais: tubos PVC, } \\
\text { porcas e parafusos de } \\
\text { carruagem, espumas de } \\
\text { isolamentos de tubos, velcro } \\
\text { e interruptores comerciais } \\
\text { Método: Foi realizada } \\
\text { adaptaçáo em um carro de } \\
\text { brinquedo para crianças } \\
\text { portadoras de necessidades } \\
\text { especiais }\end{array}$ & $\begin{array}{l}\text { País: Estados } \\
\text { Unidos } \\
\text { Local: } \\
\text { Clínicas, } \\
\text { ambulatórios } \\
\text { e domicilio. }\end{array}$ & $\begin{array}{l}\text { Paralisia Cerebral } \\
\text { Quadriplegia } \\
\text { Espástica } \\
\text { Faixa etária: } 28 \\
\text { meses } \\
\mathrm{n}=1\end{array}$ & $\begin{array}{l}\text { Funcionalidade do } \\
\text { membro superior- } \\
\text { MACS (Manual } \\
\text { Ability Classifica- } \\
\text { tion System); } \\
\text { Análise postural e } \\
\text { de estabilidade; } \\
\text { Relatório. }\end{array}$ & $\begin{array}{l}\text { Mesmo adaptado é } \\
\text { necessário supervisão } \\
\text { e modificaçôes no } \\
\text { domicílio; } \\
\text { O acento modifica- } \\
\text { do permite melhor } \\
\text { postura; } \\
\text { Luzes, vibraçōes e } \\
\text { músicas aumentam a } \\
\text { atençấo e motivaçâo. }\end{array}$ \\
\hline
\end{tabular}




\begin{tabular}{|c|c|c|c|c|c|}
\hline Autor/Ano & Método e Intervençāo & Local & Amostra & Medidas & Resultados \\
\hline $\begin{array}{l}\text { Santos; Fereira } \\
\text { (2013) }\end{array}$ & $\begin{array}{l}\text { Tipo de estudo: Relato de } \\
\text { pesquisa. } \\
\text { Método: Abordagem } \\
\text { qualitativa. } \\
\text { Entrevista com crianças } \\
\text { que realizam fisioterapia } \\
\text { em decorrência de doenças } \\
\text { crônicas } \\
\text { Duraçăo: agosto a novem- } \\
\text { bro de } 2011\end{array}$ & $\begin{array}{l}\text { País: Brasil } \\
\text { Local: } \\
\text { Hospital } \\
\text { Universitário } \\
\text { e centro de } \\
\text { fisioterapia. }\end{array}$ & $\begin{array}{l}\text { Faixa etária: seis a } \\
\text { oito anos; } \\
\text { Asma, Paralisia } \\
\text { Cerebral, afecçốes } \\
\text { crônicas do trato } \\
\text { respiratório, Dis- } \\
\text { trofia Muscular e } \\
\text { Mielomeningocele. } \\
\mathrm{n}=7\end{array}$ & $\begin{array}{l}\text { Entrevista: } \\
16 \text { perguntas } \\
\text { norteadoras que } \\
\text { partiam de quatro } \\
\text { eixos: o significado } \\
\text { da fisioterapia, os } \\
\text { momentos na fisio- } \\
\text { terapia, atividades } \\
\text { e objetivos. }\end{array}$ & $\begin{array}{l}\text { As crianças foram } \\
\text { otimistas e nāo pen- } \\
\text { sam em desistir; } \\
\text { Motivo: as consequ- } \\
\text { ências da doença; } \\
\text { Objetivos: por } \\
\text { exemplo, andar; } \\
\text { A terapia com lúdico } \\
\text { favorece o vínculo; a } \\
\text { criança deseja brin- } \\
\text { car na fisioterapia } \\
\text { e está em busca de } \\
\text { melhores condiçốes } \\
\text { físicas para brincar. }\end{array}$ \\
\hline $\begin{array}{l}\text { Huang et al. } \\
\text { (2014) }\end{array}$ & $\begin{array}{l}\text { Tipo de estudo: Relato } \\
\text { de caso. } \\
\text { Material: carro de brinque- } \\
\text { do modificado de acordo } \\
\text { com as necessidades da } \\
\text { criança } \\
\text { Duraçăo: } 15 \text { semanas, } \\
\text { sendo a primeira semana a } \\
\text { linha de base, } 12 \text { semanas } \\
\text { de intervençấo, e } 2 \text { semanas } \\
\text { pós intervençâo }\end{array}$ & $\begin{array}{l}\text { País: Estados } \\
\text { Unidos } \\
\text { Local: visita } \\
\text { domiciliar. }\end{array}$ & $\begin{array}{l}\text { Idade: } 21 \text { meses } \\
\text { Paralisia Cerebral- } \\
\text { tetraplegia espástica. } \\
\text { Sexo masculino } \\
\mathrm{n}=1\end{array}$ & $\begin{array}{l}\text { Mobilidade e } \\
\text { socializaçâa- grava- } \\
\text { çấo de vídeos ( } 20 \\
\text { minutos); } \\
\text { Avaliaçâo Pediá- } \\
\text { trica de Inventário } \\
\text { Deficiência } \\
\text { (PEDI). }\end{array}$ & $\begin{array}{l}\text { A criança apresentou } \\
\text { melhora na mobi- } \\
\text { lidade e apresentou } \\
\text { mais vocalizaçóes } \\
\text { durante as primeiras } \\
\text { semanas de inter- } \\
\text { venção. }\end{array}$ \\
\hline
\end{tabular}

Quadro 1 - Caracterização dos estudos selecionados na modalidade jogos e brincadeiras como atividade lúdica.

Fonte: elaboração própria.

\begin{tabular}{|c|c|c|c|c|c|}
\hline Autor/ Ano & Método e Intervençáo & Local & Amostra & Medidas & Resultados \\
\hline $\begin{array}{l}\text { Mckenna et al. } \\
\text { (1999) }\end{array}$ & $\begin{array}{l}\text { Tipo de estudo: Ensaio } \\
\text { clínico. } \\
\text { Método: Programa com } \\
\text { assistência de jogo de } \\
\text { computador para treina- } \\
\text { mento muscular - utilizado } \\
\text { exercícios de Kegel. } \\
\text { Follow-up: três a } 15 \text { meses }\end{array}$ & $\begin{array}{l}\text { País: Estados } \\
\text { Unidos } \\
\text { Local: Am- } \\
\text { bulatório de } \\
\text { Fisioterapia. }\end{array}$ & $\begin{array}{l}\text { Faixa etária: } \\
\text { cinco a } 11 \text { anos } \\
\text { Disfunçắo } \\
\text { miccional. } \\
\mathrm{n}=41\end{array}$ & $\begin{array}{l}\text { Relato subjetivo de: } \\
\text { enurese diurna e } \\
\text { noturna, constipaçáo } \\
\text { e sujidade fecal; } \\
\text { Urofluxometria e } \\
\text { eletromiografia. }\end{array}$ & $\begin{array}{l}90 \% \text { melhoram a enurese } \\
\text { noturna, } 89 \% \text { a enurese } \\
\text { diurna, } 100 \% \text {, constipa- } \\
\text { çâo e sujidade fecal; } \\
42 \% \text { melhoraram os pa- } \\
\text { drôes de urofluxometria } \\
\text { e eletromiografia e } 78 \% \\
\text { a contração do assoalho } \\
\text { pélvico. }\end{array}$ \\
\hline $\begin{array}{l}\text { Burdea et al. } \\
(2011)\end{array}$ & $\begin{array}{l}\text { Tipo de estudo: Relato } \\
\text { de casos. } \\
\text { Método: Reabilitação vir- } \\
\text { tual da mão utilizado Jogos } \\
\text { do PlayStation3 e luvas de } \\
\text { sensores. } \\
\text { Duração de } 14 \text { meses, } \\
\text { respectivamente. } \\
\text { Follow-up: } 14 \text { meses }\end{array}$ & $\begin{array}{l}\text { País: Estados } \\
\text { Unidos } \\
\text { Local: Resi- } \\
\text { dência dos } \\
\text { adolescentes. }\end{array}$ & $\begin{array}{l}\text { Faixa etária: } \\
\text { adolescentes até } \\
18 \text { anos } \\
\text { Hemiplegia } \\
\text { devido à } \\
\text { Traumatismo } \\
\text { Crânio-encefá- } \\
\text { lico ou Paralisia } \\
\text { Cerebral. } \\
\mathrm{n}=2\end{array}$ & $\begin{array}{l}\text { Utilização do Diâme- } \\
\text { tro de Jamar; } \\
\text { Teste de Jebsen da } \\
\text { função da mão e } \\
\text { medidas ósseas. }\end{array}$ & $\begin{array}{l}\text { Houve ganho de ampli- } \\
\text { tude articular para flexăo } \\
\text { e extensáo dos dedos; } \\
\text { Segundo o teste Jebsen } \\
\text { após } 14 \text { semanas os } \\
\text { pacientes já apresentaram } \\
\text { melhorias na execução } \\
\text { das AVD's e na minera- } \\
\text { çấo óssea. }\end{array}$ \\
\hline
\end{tabular}




\begin{tabular}{|c|c|c|c|c|c|}
\hline Autor/ Ano & Método e Intervençấo & Local & Amostra & Medidas & Resultados \\
\hline $\begin{array}{l}\text { Sandlund; Wa- } \\
\text { terworth; Häger } \\
\text { (2011) }\end{array}$ & $\begin{array}{l}\text { Tipo de estudo: Ensaio } \\
\text { clínico. } \\
\text { Método: Utilização de } 20 \\
\text { jogos interativos do Sony } \\
\text { Playstation } 2 \text { e o jogo } \\
\text { EyeToy Play } 3 \text {. } \\
\text { Duração: } 20 \text { minutos } \\
\text { por dia durante quatro } \\
\text { semanas. }\end{array}$ & $\begin{array}{l}\text { País: Suécia } \\
\text { Local: Domi- } \\
\text { cílio. }\end{array}$ & $\begin{array}{l}\text { Faixa etária: seis } \\
\text { a } 16 \text { anos } \\
\text { Paralisia Cere- } \\
\text { bral- GMFCS } \\
\text { I a III. } \\
\mathrm{n}=14\end{array}$ & $\begin{array}{l}\text { SenseWear Pro3 } \\
\text { Armband2- monitorar } \\
\text { atividade física -; } \\
\text { Acelerômetro, Inner- } \\
\text { View Professional 5.1; } \\
\text { Bateria de avaliação } \\
\text { do movimento- } \\
\text { mABC-2; } \\
\text { Teste de proficiência } \\
\text { motora- Subtest 6:5 } \\
\text { de Bruininks-Ose- } \\
\text { retsky (BOTMP); } \\
\text { Teste de Caminhada } \\
\text { de } 1 \text { minuto; } \\
\text { Diário de rotina. }\end{array}$ & $\begin{array}{l}80 \% \text { melhoram o desem- } \\
\text { penho físico } \\
\text { As crianças foram } \\
\text { classificadas como "vigo- } \\
\text { rosamente ativas" com (> } \\
3 \mathrm{MET} \text { ) com cerca de } 1 \\
\text { hora e meia por dia; } \\
\text { Houve melhora no } \\
\text { equilíbrio e no MABC-2 } \\
\text { em destreza manual. }\end{array}$ \\
\hline $\begin{array}{l}\text { Howcroft et al. } \\
\text { (2012) }\end{array}$ & $\begin{array}{l}\text { Tipo de estudo: Experi- } \\
\text { mental. } \\
\text { Método: Grupo único } \\
\text { Jogos ativos: boliche, tênis, } \\
\text { boxe e dança; } \\
\text { Wii Sports e Dance Dance } \\
\text { Revolutoion - os pacientes } \\
\text { foram monitorizados por } \\
\text { marcadores reflexivos. } \\
\text { Duração: } 13 \text { minutos de } \\
\text { jogos }\end{array}$ & $\begin{array}{l}\text { País: Canadá } \\
\text { Local: La- } \\
\text { boratório de } \\
\text { movimento. }\end{array}$ & $\begin{array}{l}\text { Faixa etária: } \\
\text { idade média de } \\
\text { nove anos } \\
\text { Paralisia } \\
\text { Cerebral. } \\
\mathrm{n}=17\end{array}$ & $\begin{array}{l}\text { Cinemática -sistema } \\
\text { óptico de captura; } \\
\text { Gasto energéti- } \\
\text { co- Unidade de } \\
\text { Teste Cardiopulmonar } \\
\text { portátil; } \\
\text { Ativaçâo do membro } \\
\text { superior- eletrodos de } \\
\text { superfície; } \\
\text { Escala OMNI de } \\
\text { percepção; } \\
\text { Escala de Prazer Ativi- } \\
\text { dade Física (PACES). }\end{array}$ & $\begin{array}{l}\text { Graus moderados de } \\
\text { atividade física foram } \\
\text { atingidos durante os } \\
\text { jogos de dança e boxe; } \\
\text { Velocidades e aceleraçóes } \\
\text { angulares foram maiores } \\
\text { no braço dominante } \\
\text { do que no braço hemi- } \\
\text { plégico durante o jogo } \\
\text { bilateral; } \\
\text { Alto grau de satisfação } \\
\text { foi relatado na PACES; } \\
\text { Grande mobilidade dos } \\
\text { MMII, o Wii Bowling } \\
\text { promoveu uma gama } \\
\text { maior de movimentos } \\
\text { bilaterais dos MMSS. }\end{array}$ \\
\hline $\begin{array}{l}\text { Abdulsatar et al. } \\
(2013)\end{array}$ & $\begin{array}{l}\text { Tipo de estudo: Ensaio } \\
\text { clínico. } \\
\text { Método: Orientação para } \\
\text { jogar o Nintendo Wii } \\
\text { Box. } \\
\text { Duraçāo: Dois dias, duas } \\
\text { vezes por dia, durante } 10 \\
\text { minutos }\end{array}$ & $\begin{array}{l}\text { País: Canadá } \\
\text { Local: Uni- } \\
\text { dade de cui- } \\
\text { dados críticos } \\
\text { pediátricos. }\end{array}$ & $\begin{array}{l}\text { Faixa etária: } \\
\text { três a } 18 \text { anos } \\
\text { Criticamente } \\
\text { doentes- em } \\
\text { uso de ventila- } \\
\text { ção mecânica. } \\
\mathrm{n}=8\end{array}$ & $\begin{array}{l}\text { Actigrafh GT3X; para } \\
\text { medir atividade física; } \\
\text { Gripa Dynanometer } \\
\text { TM; ou Vigorimeter } \\
\text { Martin- Para medir } \\
\text { força de preensão da } \\
\text { măo. }\end{array}$ & $\begin{array}{l}25 \% \text { dos pacientes ultra- } \\
\text { passaram a prescriçáo do } \\
\text { exercício; } \\
\text { Houve aumento da ativi- } \\
\text { dade do MMSS durante } \\
\text { o jogo Wii; } \\
\text { Houve diferença na força } \\
\text { de preensão e a média de } \\
\text { força no quarto dia foi } \\
114,4 \% \text { maior. }\end{array}$ \\
\hline
\end{tabular}




\begin{tabular}{|c|c|c|c|c|c|}
\hline Autor/Ano & Método e Intervençáo & Local & Amostra & Medidas & Resultados \\
\hline $\begin{array}{l}\text { Hammond et } \\
\text { al. (2014) }\end{array}$ & $\begin{array}{l}\text { Tipo de estudo: Estudo } \\
\text { controlado randomizado } \\
\text { crossover. } \\
\text { Método: } \\
\text { Grupo intervençāo (A): } \\
\text { Nintendo Wii Fit durante } \\
\text { a pausa para o almoço; } \\
\text { Grupo comparaçáo (B): } \\
\text { programa regular de saltos. } \\
\text { Duraçăo: quatro semanas } \\
\text { cada fase, sendo grupo } \\
\text { A três vezes por semana } \\
\text { durante } 10 \text { minutos e B } 60 \\
\text { minutos por semana }\end{array}$ & $\begin{array}{l}\text { País: Reino } \\
\text { Unido } \\
\text { Local: Escolas } \\
\text { primárias. }\end{array}$ & $\begin{array}{l}\text { Faixa etária: } \\
\text { sete a } 10 \text { anos } \\
\text { Crianças com } \\
\text { Desordem de } \\
\text { Coordenaçáo } \\
\text { Motora. } \\
\mathrm{n}=20\end{array}$ & $\begin{array}{l}\text { Teste de Bruininks- } \\
\text {-Oseretsky (BOT-2); } \\
\text { para medir a profici- } \\
\text { ência motora ; } \\
\text { Questionário de } \\
\text { Habilidades e coorde- } \\
\text { naçáo (CSQ); } \\
\text { Questionário de faci- } \\
\text { lidades e dificuldades } \\
\text { (SDQ). }\end{array}$ & $\begin{array}{l}\text { O grupo A apresentou } \\
\text { desenvolvimento no } \\
\text { BOT-2 e CSQ positivo; } \\
\text { Ganhos motores no } \\
\text { BOT-2 e as crianças } \\
\text { relataram percepção, } \\
\text { adesão ao tratamento e } \\
\text { bem estar; } \\
\text { Ganhos significativos em } \\
\text { relação a coordenação } \\
\text { motora, percepçáo da } \\
\text { criança de sua capacidade } \\
\text { motora; } \\
\text { Houve relatos de bem- } \\
\text {-estar emocional para } \\
\text { muitos, mas nem todas } \\
\text { as crianças. }\end{array}$ \\
\hline $\begin{array}{l}\text { Parry et al. } \\
(2014)\end{array}$ & $\begin{array}{l}\text { Tipo de estudo: Descritivo } \\
\text { observacional. } \\
\text { Método: Aplicação de } \\
\text { jogos interativos e de RV } \\
\text { (Xbox Kinect e Playstation } \\
\text { 3). } \\
\text { Duraçāo: três vezes por } \\
\text { semana, por duas semanas. }\end{array}$ & $\begin{array}{l}\text { País: Estados } \\
\text { Unidos } \\
\text { Local: Am- } \\
\text { bulatório de } \\
\text { Fisioterapia. }\end{array}$ & $\begin{array}{l}\text { Faixa etária: } \\
\text { idade média de } \\
10 \text { anos } \\
\text { Vítimas de } \\
\text { queimaduras. } \\
\mathrm{n}=30\end{array}$ & $\begin{array}{l}\text { Análise quantitativa } \\
\text { tridimensional do mo- } \\
\text { vimento dos membros } \\
\text { superiores, por meio } \\
\text { de reflexores anexados } \\
\text { a pele e captura cinéti- } \\
\text { ca dos dados. }\end{array}$ & $\begin{array}{l}\text { A flexão e adução } \\
\text { máxima do ombro, e } \\
\text { flexāo do cotovelo foram } \\
\text { maiores ao jogar o Kinect } \\
(\leq 0.01) \text {; } \\
\text { O tempo de elevaçáo } \\
\text { dos braços acima de } 120 \\
{ }^{\circ} \text { foi significativamente } \\
\text { superior com Kinect (p } \\
<0.05 \text { ); } \\
\text { Ambos videogames } \\
\text { mostraram ter potencial } \\
\text { terapêutico. }\end{array}$ \\
\hline $\begin{array}{l}\text { Salem, Elokda } \\
\text { (2014) }\end{array}$ & $\begin{array}{l}\text { Tipo de estudo: Estudo } \\
\text { duplo-cego randomizado } \\
\text { controlado. } \\
\text { Método: } \\
\text { Grupo experimental (Wii): } \\
\text { Nintendo Wii Sports e } \\
\text { Wii Fit } \\
\text { Grupo controle: fisiotera- } \\
\text { pia convencional. } \\
\text { Duração: duas sessôes } \\
\text { semanais durante } 10 \\
\text { semanas }\end{array}$ & $\begin{array}{l}\text { País: Estados } \\
\text { Unidos } \\
\text { Local: Am- } \\
\text { bulatório de } \\
\text { Fisioterapia. }\end{array}$ & $\begin{array}{l}\text { Faixa etária: } 39 \\
\text { a } 58 \text { meses } \\
\text { Atraso de de- } \\
\text { senvolvimento. } \\
\mathrm{n}=40\end{array}$ & $\begin{array}{l}\text { Teste de sentar e } \\
\text { levantar; } \\
\text { Teste de permanecer } \\
\text { em uma perna só; } \\
\text { Velocidade da marcha; } \\
\text { Teste de subir e descer } \\
\text { escadas; } \\
\text { Teste de caminhada } \\
\text { de } 2 \text { minutos; } \\
\text { Força de preensão; } \\
\text { Medida de Função } \\
\text { Motora-GMFM. }\end{array}$ & $\begin{array}{l}\text { experimental demons- } \\
\text { trou melhoras na prova } \\
\text { de apoio monopodal, } \\
\text { força de preensăo da máo } \\
\text { direita e força de aperto } \\
\text { na máo esquerda ; } \\
\text { Não houve diferenças } \\
\text { nos outros desfechos, } \\
\text { na comparaçáo entre os } \\
\text { grupos. }\end{array}$ \\
\hline $\begin{array}{l}\text { Trost et al. } \\
(2014)\end{array}$ & $\begin{array}{l}\text { Tipo de estudo: Ensaio } \\
\text { Clínico Randomizado. } \\
\text { Método: } \\
\text { Grupo 1: programa de } \\
\text { jogos ativos, com Xbox } \\
\text { e Kinect em um jogo de } \\
\text { desporto ; } \\
\text { Grupo 2: Programa de } 2 \\
\text { jogos, que exigiram menos } \\
\text { mobilidade. } \\
\text { Duração: } 16 \text { sessóes sema- } \\
\text { nais durante } 16 \text { semanas }\end{array}$ & $\begin{array}{l}\text { País: Estados } \\
\text { Unidos } \\
\text { Local: } \\
\text { Escolas. }\end{array}$ & $\begin{array}{l}\text { Faixa etária: } 12 \\
\text { a } 18 \text { anos } \\
\text { Crianças sobre- } \\
\text { peso e obeso. } \\
\mathrm{n}=75\end{array}$ & $\begin{array}{l}\text { Acelerômetro } \\
\text { (GT3X); } \\
\text { Estadiômetro. }\end{array}$ & $\begin{array}{l}\text { A taxa de retenção global } \\
\text { foi de } 80 \% \text {; } \\
\text { O grupo } 2 \text { apresentou } \\
\text { aumento na atividade } \\
\text { diária e maiores reduçóes } \\
\text { nas percentagens de } \\
\text { excesso e acúmulo de } \\
\text { peso. }\end{array}$ \\
\hline
\end{tabular}

Quadro 2 - Caracterização dos estudos selecionados na modalidade jogos eletrônicos e realidade virtual (RV).

Fonte: elaboração própria. 
O estudo que envolveu a modalidade mista foi o de Ferguson et al. (2013), trata-se de estudo quase experimental que comparou a eficácia de duas modalidades: o treinamento de habilidade neuromotora (37 participantes) com o Wii Fit (19 participantes) em crianças de seis a 10 anos, com Desordem de Coordenação do Desenvolvimento. Para o treinamento de habilidade neuromotora foi proposto atividades lúdicas como futebol e jogos do tipo "bola queimada", utilizando equipamentos simples como bolas, paus, tábuas, baldes, copos e tijolos, com sessóes de 60 minutos, realizadas duas vezes por semana, por nove semanas, Enquanto que para o grupo que realizou a intervenção do Wii Fit foi proposto a utilização de cinco jogos utilizando a plataforma de equilíbrio, e ainda, 13 jogos que simulavam a realidade de andar de bicicleta, skate e jogo de esqui, num período de seis semanas, três vezes por semana. As medidas de desfecho foram Dinamômetro para força de preensão manual, a bateria de avaliação de movimento- $\mathrm{mABC}-2$, medida de força funcional, teste de performance anaeróbica "Muscle Power Sprint Test" (MPST) e o teste de corrida "shuttle run" de 20 metros. Os resultados mostraram benefícios para ambos os grupos, porém o grupo de treinamento de habilidade neuromotora obteve resultados superiores nas medidas de proficiência motora, cardiorrespiratória, aptidão física e força funcional.

A atividade lúdica deve ser sempre, que possível, associada ao processo de reabilitação, pois o brincar faz parte da infância. Ao utilizar as atividades lúdicas vinculadas à terapia proporciona humanização, melhor relacionamento terapeuta-paciente, adesão ao tratamento e, com isso, melhora cognitiva, motora, sensorial e social (BRUNELLO, 2001; AZEVEDO, 2007; SCHENKEL et al., 2013). No presente estudo foram observados benefícios da utilização da atividade lúdica como coadjuvante na fisioterapia em diversas populaçóes e condiçóes pediátricas, como: lactentes, crianças com câncer, paralisia cerebral, disfunção miccional, vítimas de queimaduras, atraso no desenvolvimento motor, desordem de coordenação motora, crianças com sobrepeso e obesas. Apesar de haver pesquisas envolvendo a atividade lúdica nas diversas áreas da saúde, há necessidade de mais estudos no contexto da fisioterapia em pediatria, uma vez que grande parte dos estudos que trazem essa abordagem como tema principal esta voltada à área da psicologia, sendo a ludoterapia modalidade terapêutica da psicologia, porém, não restringe a utilização da atividade lúdica em outras áreas da saúde (AZEVEDO, 2007), já que o brincar e as brincadeiras fazem parte do universo infantil e, com isso, deveriam ser considerados na prática de todos profissionais de saúde envolvidos com essa população.

Segundo Feigelman (2009), atividade lúdica é um tema abrangente, pois o brincar envolve características sociais, culturais e individuais, entretanto, cada população, ou até mesmo cada criança desenvolve as brincadeiras conforme sua aptidão e contato social. Nesse aspecto, e considerando as diferenças culturais, foram encontrados estudos de diferentes partes do mundo: Estados Unidos, Reino Unido, Canadá, Suécia, Brasil e Japão, tornando possível categorizá-los em duas abordagens diferentes de atividade lúdica, sendo elas a modalidade de jogos e brincadeiras e a modalidade de jogos eletrônicos e RV.

Em essência, o desenvolvimento de habilidades motoras nos primeiros anos de vida constitui o alicerce para permitir que a criança controle seu corpo e interaja com o meio ambiente, assim, realiza movimentos cada vez mais complexos fundamentais para as atividades diárias. Essa complexidade envolvida no controle motor é conduzida não apenas pela maturação do sistema nervoso central, mas também requer suporte do ambiente ou contexto 
em que a criança está inserida, bem como, das oportunidades para adquirir e aperfeiçoar tais habilidades (FAVAZZA; SIPERSTEIN, 2016). Sabe-se que o desenvolvimento motor típico não ocorre para todas as crianças, sendo que em algumas situaçóes elas podem experimentar dificuldades relacionadas à estabilidade, equilíbrio postural, locomoção e manipulação de objetos (FAVAZZA; SIPERSTEIN, 2016). Nesse sentido, foi possível identificar duas abordagens distintas nos estudos relacionados na presente revisão, devido as suas características: 1) a modalidade de jogos e brincadeiras que promoveram terapia diversificada, sendo os recursos utilizados de fácil acesso e baixo custo, como bolas, brinquedos, bastão ou até mesmo adaptaçóes em objetos do cotidiano, como carrinhos e andadores; 2) modalidade de RV e jogos eletrônicos, que foi a mais utilizada nos estudos levantados, abrangendo o Xbox Kinect, Playstation 3, Nintendo Wii, Sony Playstation 2 entre outros, destaca-se o aspecto da motivação, devido a interação que os jogos promovem, melhor adesão ao tratamento, bem estar e a facilidade da utilização em clínicas, casas, hospitais, o que enriquece a terapia e motiva a criança no tratamento (HUANG et al., 2014; PARRY et al., 2014; BURDEA et al., 2011).

A escolha de jogos e brincadeiras na terapia deve ser realizada levando em consideração a faixa etária dos pacientes e a condição de saúde ou funcionalidade. No presente estudo foi observado que a escolha do recurso lúdico estava adequada para a população envolvida, como exemplo, o estudo de Jill, Heathcock e Galloway (2009), que utilizou em seu estudo brinquedos com barulhos, vibraçóes e cores para população que era de neonatos prematuros com idade de 33 semanas. Segundo as diretrizes de estimulação precoce (BRASIL, 2016), a intervenção e momento oportuno, ou seja, nos primeiros anos de vida, de bebês em risco para o desenvolvimento neuropsicomotor, é fundamental, e os aspectos envolvidos com o desenvolvimento dos movimentos e controle motor englobam momentos lúdicos de estimulação vestibular, proprioceptiva, tátil, auditiva e visual (utilizando técnicas/ intervenções terapêuticas e recursos lúdicos). A experiência perceptual e motora, ao invés de servir simplesmente como entrada e saída para uma estrutura cognitiva independente, quando ocorre de maneira contextualizada (contextos ambiental, social e cultural) mantém e altera a cognição ativamente, isto é, contribui para o aprendizado motor (LOBO et al., 2013).

O Yoga também é considerado recurso lúdico (BRUNELLO, 2001), e foi utilizado no contexto de internação em Unidade de Reumatologia e Oncologia, a fim de melhorar os sintomas de ansiedade, fadiga, dores musculares e perturbaçóes do sono, sintomas presentes em crianças hospitalizadas por longo período de tempo (THYGESON et al., 2010). Também é possível a adaptação de objetos para melhora de qualidade de vida e reabilitação, sendo que, a adaptação de carros de brinquedos feita por meio de materiais de fácil acesso, como tubos de PVC, espumas, luzes, faixas e sons, pode melhorar a mobilidade e interação social de crianças com paralisia cerebral no ambiente domiciliar (HUANG et al., 2014; GALOOWAY, 2012).

Por fim, a maior parte dos achados incluiu a modalidade jogos eletrônicos e RV, com destaque para jogos considerados como ativos, ou seja, exigem ampla movimentação do jogador. A interaçáo da criança com ambiente de RV se dá por meio da movimentaçáo corporal, que é detectada por meio de sensores que captam a movimentação em três dimensóes, criando imagens interativas que aparecem na tela do televisor (SOARES et al., 2015; PAVÃO et al., 2014). No geral, a maioria dos estudos mostrou utilizar esses jogos para estimular a movimentação de membros superiores, melhorar força de preensão e aumentar a atividade física; porém 
também foram utilizados para treinamento muscular em crianças com disfunção miccional (MCKENNA et al., 1999) e melhora da coordenação motora em crianças com Desordem de Coordenação Motora (HAMMOND et al., 2014). Apesar das diversas possibilidades do uso de jogos eletrônicos e RV não há consenso na literatura a cerca de qual o tempo de utilização, frequência semanal e duração do tratamento que seria o mais adequado nas diferentes populações estudadas.

Em relação ao local da intervenção, foi possível observar que há possibilidade de uso da atividade lúdica como coadjuvante da fisioterapia em diversos contextos, hospitais, ambulatórios, residência e também no ambiente escolar. Do total, cinco estudos utilizaram o domicílio como local de estudo e dois o ambiente escolar, este envolvimento com o ambiente em que a criança está inserida e seus cuidadores/familiares tem sido reforçado em muitos estudos envolvendo a população pediátrica. Favazza e Siperstein (2016) destacam que é de fundamental importância os programas monitorizados incluirem membros da família e colegas em experiências positivas de brincadeiras que trabalhem o aspecto motor, uma vez que têm o potencial de influenciar favoravelmente o desenvolvimento global.

$\mathrm{Na}$ prática clínica, a reabilitação pediátrica inclui o reconhecimento da mudança como fenômeno multideterminado, que envolve fatores comuns relacionados ao papel do terapeuta na criação de condiçóes facilitadoras de mudança (por meio de relacionamentos de suporte, expectativas positivas e experiências de domínio e aprendizagem) e ao treinamento de habilidades em parceria colaborativa, sendo que a abordagem deve ser realizada em contexto significativo para a criança; já que, as experiências de domínio e aprendizagem, que englobam novos comportamentos, novas aprendizagens e reformulação, são criadas por meio de oportunidades e exposição a atividades terapeuticamente relevantes (KING, 2016). Ao considerar a percepção da criança em relação ao uso de atividades lúdicas em terapia, em um dos estudos analisados (SANTOS; FEREIRA, 2013), foi possível observar que crianças que realizam fisioterapia no tratamento de doenças crônicas como asma, paralisia cerebral, distrofia muscular, percebem o uso da atividade lúdica de forma positiva, e buscam melhores condiçóes físicas para conseguir brincar. Portanto, com a utilização de atividades lúdicas a fisioterapia não se torna desmotivadora, cada limitação é analisada e o jogo ou brincadeira deve permitir ganhos funcionais e melhor qualidade de vida para as crianças. Deve se considerar que, cada criança é um ser diferente e sua individualidade deve ser respeitada, e o brincar sempre que possível deve ser incorporado ao seu tratamento.

\section{Conclusão}

$\mathrm{Na}$ prática da fisioterapia pediátrica foi possível identificar duas categorias para o uso de atividades lúdicas como coadjuvantes terapêuticos, jogos e brincadeiras e jogos eletrônicos e realidade virtual. Ambas as categorias mostraram benefícios e boa aceitação pelas crianças envolvidas, sendo que na categoria jogos e brincadeiras foram destacados desfechos positivos relacionados à maior interação com o brinquedo, melhora na postura e equilíbrio corporal, motivação, fortalecimento de vínculo, maior mobilidade, redução de sintomas de dor, fadiga, ansiedade e distúrbios de sono; já na categoria realidade virtual, destaca-se a melhora da função de assoalho pélvico, melhora no desempenho físico, equilíbrio, destreza, força de preensão e 
movimentação dos membros superiores e maior satisfação com a terapia. Além disso, é importante destacar que esses recursos podem ser utilizados para o tratamento de diversas disfunçóes, bem como, em diferentes contextos (hospital, ambulatório, domicílio e escolas), promovendo ganhos específicos para cada condição do paciente, mas principalmente a funcionalidade. Assim, o brincar como recurso terapêutico deve ser sempre vinculado ao tratamento da criança, uma vez que brincar faz parte da infância e promove diversos benefícios, e também maior adesão ao tratamento e humanização na área da saúde.

\section{REFERÊNCIAS}

ABDULSATAR, F. et al. "Wii-Hab" in critically ill children: A pilot trial. Journal of Pediatric Rehabilitation Medicine, Netherland, v.6, n.1, p.193-204, 2013.

ABRANTES, M.M.; LAMOUNIER, J.A.; COLOSIMO, E.A. Prevalência de sobrepeso e obesidade em crianças e adolescentes das regiōes Sudeste e Nordeste. Jornal de pediatria, Rio de Janeiro, v.78, n.4, p.335-340, 2002.

AZEVEDO, D.M. et al. O brincar como instrumento terapêutico na visão da equipe de saúde. Ciência, cuidado e saúde, Maringá, v.6, n.3, p.335-341, 2007.

BORGES, E.P.; NASCIMENTO, M.D.S.B.; SILVA, S.M. Benefícios das atividades lúdicas na recuperação de crianças com câncer. Boletim Academia Paulista de Psicologia, São Paulo, v.2, n.2, p.211221, 2008.

BRASIL. Ministério da Saúde. Secretaria de Políticas de Saúde. Departamento de Atenção Básica. Saúde da criança: acompanhamento do crescimento e desenvolvimento infantil. Ministério da Saúde. Secretaria de Políticas de Saúde. Brasília: Ministério da Saúde, 2002.

BRASIL. Ministério da Saúde. Secretaria de Atenção à Saúde. Diretrizes de estimulação precoce: crianças de zero a 3 anos com atraso no desenvolvimento neuropsicomotor decorrente de microcefalia. Ministério da Saúde. Secretaria de Atenção à Saúde. Brasília: Ministério da Saúde, 2016.

BRUNELLO, M.I.B. Ser lúdico: promovendo a qualidade de vida na infância com deficiência. 2001. Tese (Doutorado em Psicologia Escolar e do Desenvolvimento Humano) - Instituto de psicologia, Universidade de São Paulo, São Paulo, 2001.

BRUNELLO, M.I. et al. A criação de um espaço para existência: o espaço lúdico terapêutico. Revista de terapia ocupacional da Universidade de São Paulo. São Paulo, v.17, n.1, p.4-9, 2006.

BURDEA, G.C. et al. Long-term hand tele-rehabilitation on the playstation 3: Benefits and Challenges. Research Gate, Massachusetts, v.1, n.1, p.1835-8, 2011.

CORDEIRO, M. O livro da criança: do 1 ao 5 anos. 5. ed. Lisboa: A esfera dos livros, 2007.

FAVAZZA, P.C., SIPERSTEIN, G.N. Motor skill acquisition for young children with disabilities. In: REICHOW, B. (Ed.). Handbook of Early Childhood Special Education. Springer, Cham, 2016.

FEIGELMAN, S. A criança pré-escolar. Rio de Janeiro: Elsevier, 2009.

FERGUSON, G.D. et al. The efficacy of two task-orientated interventions for children with developmental coordination disorder: neuromotor task training and nintendo Wii Fit training. Research in Developmental Disabilities, Amsterdam, v.34, n.9, p.2449-61, 2013. 
FUJISAWA, D.S.; MANZINI, E.J. Formação acadêmica do fisioterapeuta: a utilização das atividades lúdicas nos atendimentos de crianças. Revista brasileira de educaçáo especial, Piracicaba, v.12, n.1, p.6584, 2006.

HAMMOND, J. et al. An investigation of the impact of regular use of the Wii Fit to improve motor and psychosocial outcomes in children with movement difficulties: A pilot study. Child Care Health Development, Nova Jersey, v.2, n.40, p.165-75, 2014.

HOWCROFT, J. et al. Active video game play in children with cerebral palsy: Potential for physical activity promotion and rehabilitation therapies. Archives of physical medicine and rehabilitation, Chicago, v.93, n.1, p.1448-56, 2012.

HUANG, H.; GALLOWAY, J.C. Modified ride-on toy cars for early power mobility: A technical report. Pediatric physical therapy, Baltimore, v.2, n.24, p.149-154, 2012.

HUANG, H. et al. Modified toy cars for mobility and socialization: case report of a child with cerebral palsy. Pediatric physical therapy, Baltimore, v.26, n.1, p.76-84, 2014.

JILL, C.; HEATHCOCK, J. C.; GALLOWAY, C. Exploring Objects With Feet Advances Movement in Infants Born Preterm: A Randomized Controlled Trial. Physical Therapy, New York, v.89, n.10, p.1027-1038, 2009.

KING, G. The role of the therapist in therapeutic change: how knowledge from mental health can inform pediatric rehabilitation. Physical \& Occupational Therapy In Pediatrics, 2016.

LOBO, M.A. et al. Grounding early intervention: physical therapy cannot just be about motor skills anymore. Physical Therapy, New York, v.93, p.94-103, 2013.

McKENNA, P. et al. Pelvic floor muscle retraining for pediatric voiding dysfunction using interactive computer games. Journal of urology, Baltimore, v.162, n.3, p.1056-1062, 1999.

MOURA-RIBEIRO, M.V.L.; GOLÇALVES, V.M.G. Neurologia do desenvolvimento da criança. 2.ed. Rio de Janeiro: Revinter, 2010.

PARRY, I. et al. Keeping up with video game technology: objective analysis of Xbox Kinect ${ }^{\mathrm{TM}}$ and PlayStation $3 \mathrm{Move}^{\mathrm{TM}}$ for use in burn rehabilitation. Burns, Gildford, v.40, n.5, p.852-859, 2014.

PAVÃO, S.L. et al. Impacto de intervenção baseada em realidade virtual sobre o desempenho motor e equilíbrio de uma criança com paralisia cerebral: estudo de caso. Revista paulista de pediatria, São Paulo, v.32, n.4, p.389-394, 2014.

POSTIAUX, G. Fisioterapia respiratória pediátrica: o tratamento guiado por ausculta pulmonar. 2.ed. Porto Alegre: Artmed, 2004.

POUNTNEY, T. Fisioterapia pediátrica. Rio de Janeiro: Elsevier, 2008.

SALEM, Y.; ELOKDA, A. Use of virtual reality gaming systems for children who are critically ill. Journal of Pediatric Rehabilitation Medicine, Amsterdam, v.7, n.3, p.273-6, 2014.

SANDLUND, M.; WATERWORTH, E.L.; HÄGER, C. Using motion interactive games to promote physical activity and enhance motor performance in children with cerebral palsy. Developmental neurorehabilitation, London, v.14, n.1, p.15-21, 2011.

SANTOS, E.C.; RAMOS, A.S.; SOUSA, E.A. Atendimento pediátrico humanizado, reação da criança e satisfação dos pais no serviço público e privado de fisioterapia respiratória. Estação Científica (UniFap), Macapá, v.1, n.2, p.69-84, 2011. 
SANTOS, K.P.B.; FERREIRA, V.S. Contribuiçóes para a fisioterapia a partir dos pontos de vista das crianças. Revista Brasileira de Educaçâo Especial, Marília, v.19, n.2, p.211-224, 2013.

SCHENKEL, I.C.; et al. Brinquedo terapêutico como coadjuvante fisioterapêutico de crianças com afecçóes respiratórias. Revista Psicologia: teoria e prática, São Paulo, v.15, n.1, p.130-144, 2013.

SILVA, R.R.; IWABE-MARCHESE, C. Uso da realidade virtual na reabilitação motora de uma criança com paralisia cerebral atáxica: estudo de caso. Fisioterapia e pesquisa, São Paulo, v.22, n.1, p.97102, 2015.

SOARES, M.D. et al. Wii reabilitação e fisioterapia neurológica: uma revisão sistemática. Revista neurociências, São Paulo, v.23, n.1, p.81-88, 2015.

THYGESON, M. et al. Peaceful play yoga: Serenity and balance for children with cancer and their parents. Journal of pediatric oncology nursing, Philadelphia, v.27, n.5, p.276-284, 2010.

TROST, S. G. et al. Effects of a pediatric weight management program with and without active video games a randomized trial. JAMA Pediatrics, Chicago, v.168, n.5, p.407- 413, 2014. 
SILVA, A.S.; VALENCIANO, P.J.; FUJISAWA, D.S. 